\title{
Citation
}

Myer, Angela. "Tropical Paradise: Its Light and Its Shadows."

Powerpoint presentation. Refereed Proceedings of the Inaugural

Tropics of the Imagination Conference, 2-3 November 2009. etropic: electronic journal of studies in the tropics, Vol 9 (2010), <http://

www.jcu.edu.au/etropic> 


\section{Tropical Paradise: \\ Its Light and Its Shadows}

\section{Angela Myer}

To define the inherent quality found in the tropical paintings of Far North Queensland and locate this research in the context of Australian paintings - considering whether this is a unique chapter in Australian Art. 


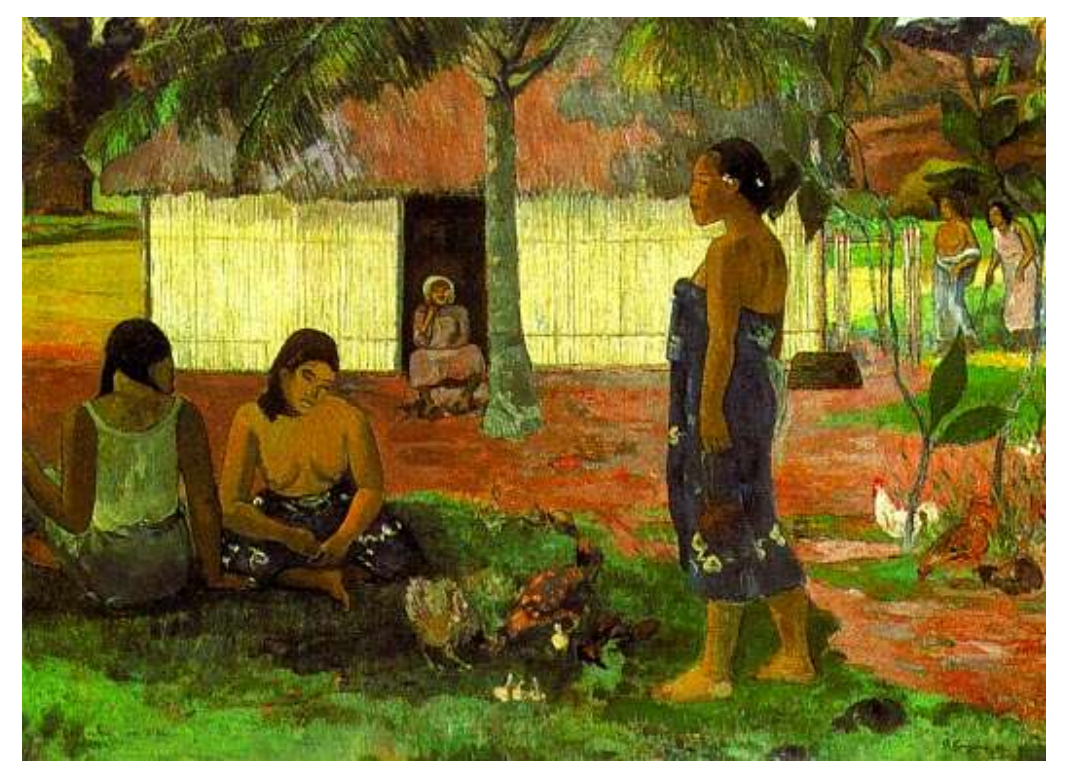

This notion of tropical light is compared to the aesthetics of tropical paintings by artists such as Gauguin and Matisse. Specifically North Queensland occupies a wet tropic zone, and this contributes to a particular visual stimulus. 


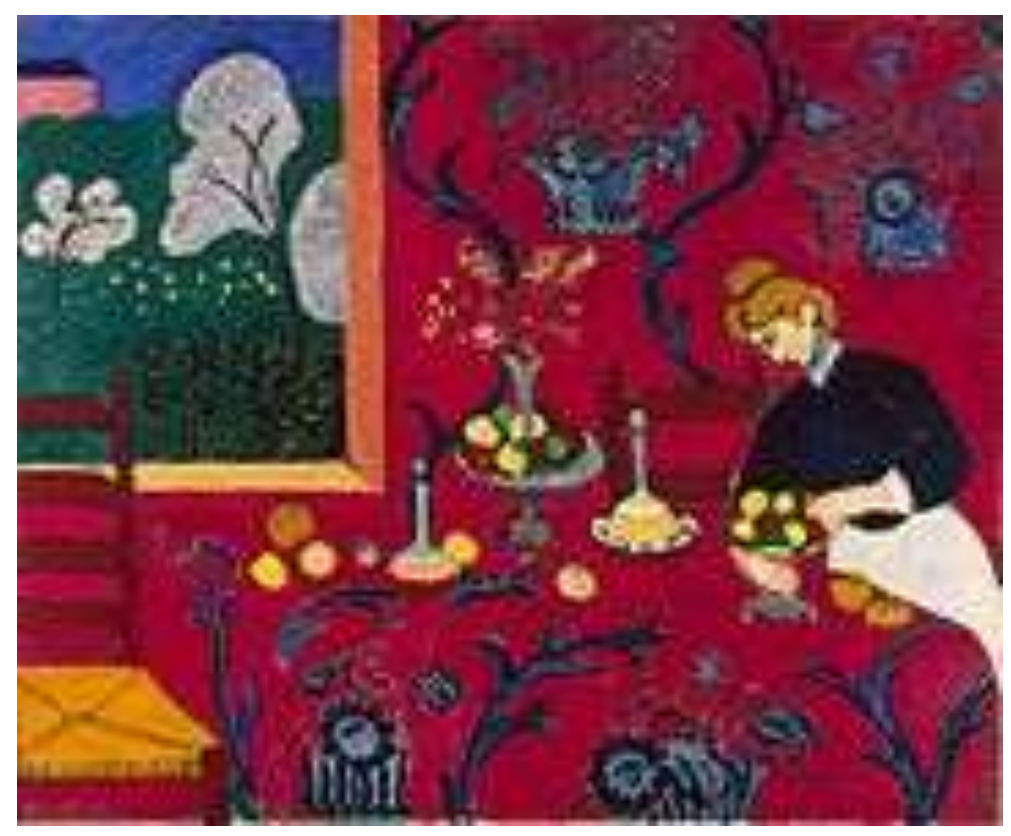

The research builds on European traditions of paintings of the exotic and Orient, via largely French influences. 


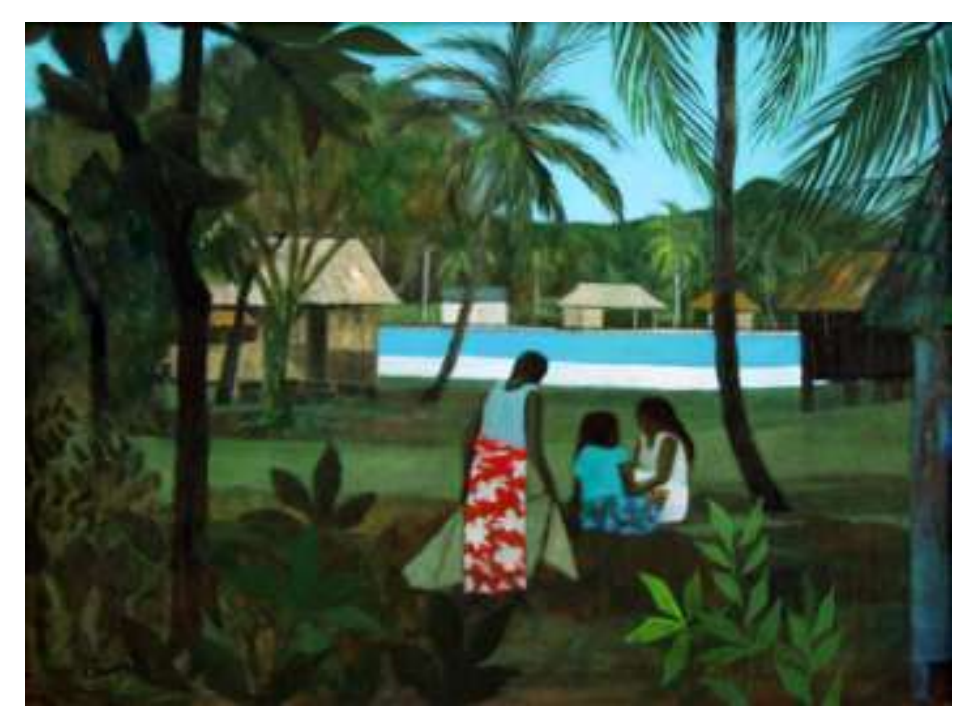

Extending into the Pacific Ocean Ray Crooke empathised with the island lifestyle and the casual attitudes which were advantageous for an artist looking for models to draw. 


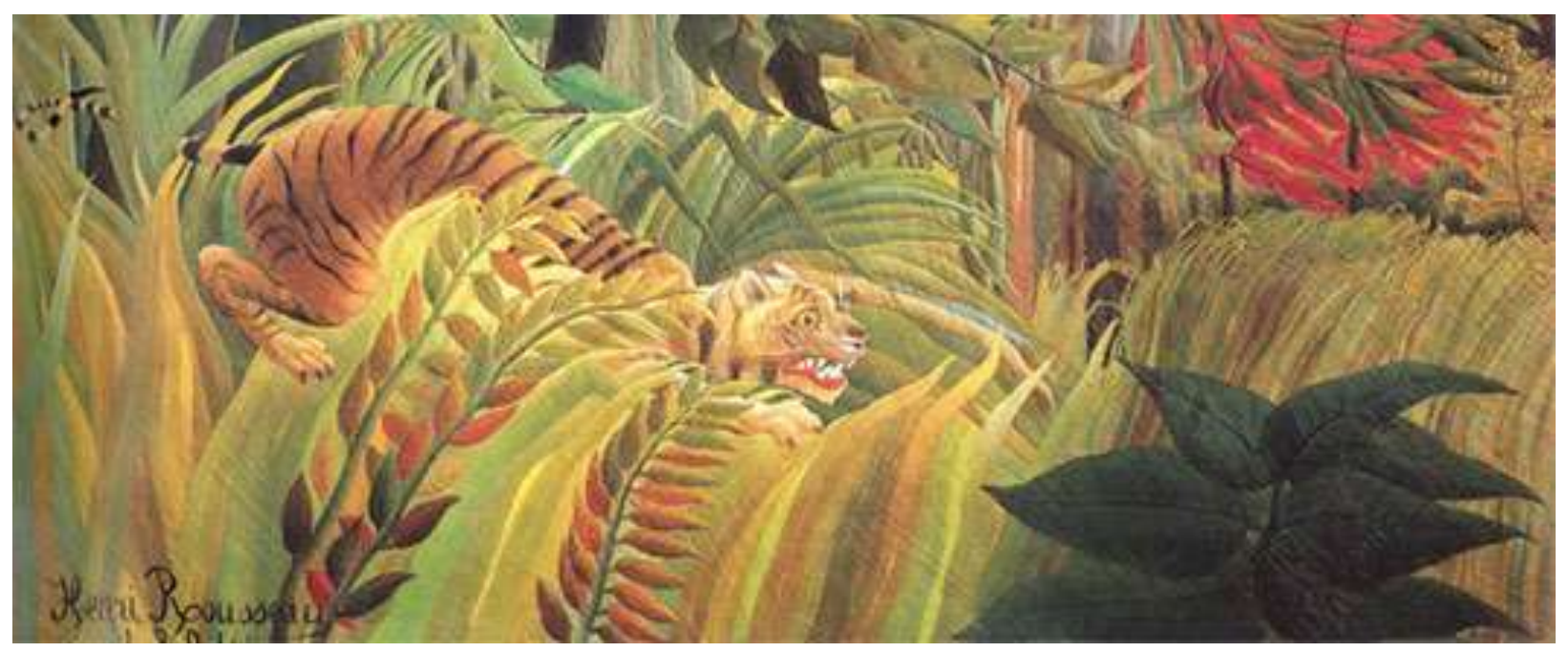

"When I go into the glass houses and I see the strange plants of exotic lands, it seems to me that I enter into a dream." Living in tropical North Queensland may inhabit a Rousseau dream. 


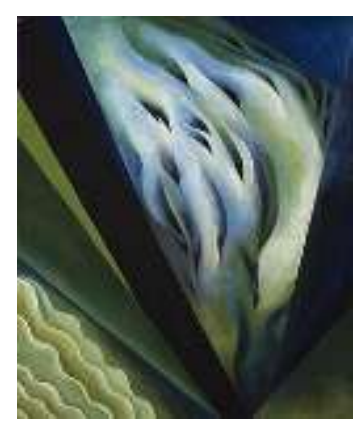

With a fascination for floral motifs Georgia O'Keeffe participated in a changing aesthetic of modernism. Her iconography is rooted in shells, rocks, bones and flowers as well as spacious landscapes which morph into luscious abstractions through her delicate watercolours. 


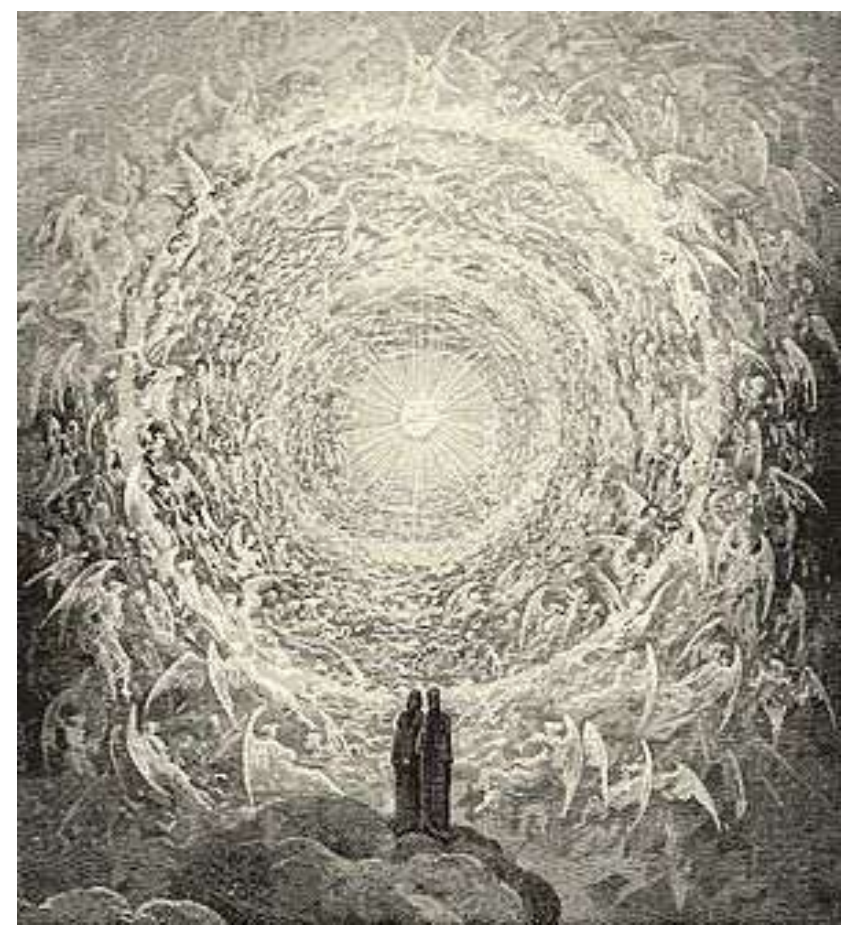

Italo Calvino suggests that "our ability to desire a different kind of life, and our very way of looking at the world: as a total way of looking that sets us inwardly free to free ourselves outwardly." (Calvino: 1987, p. 222) 


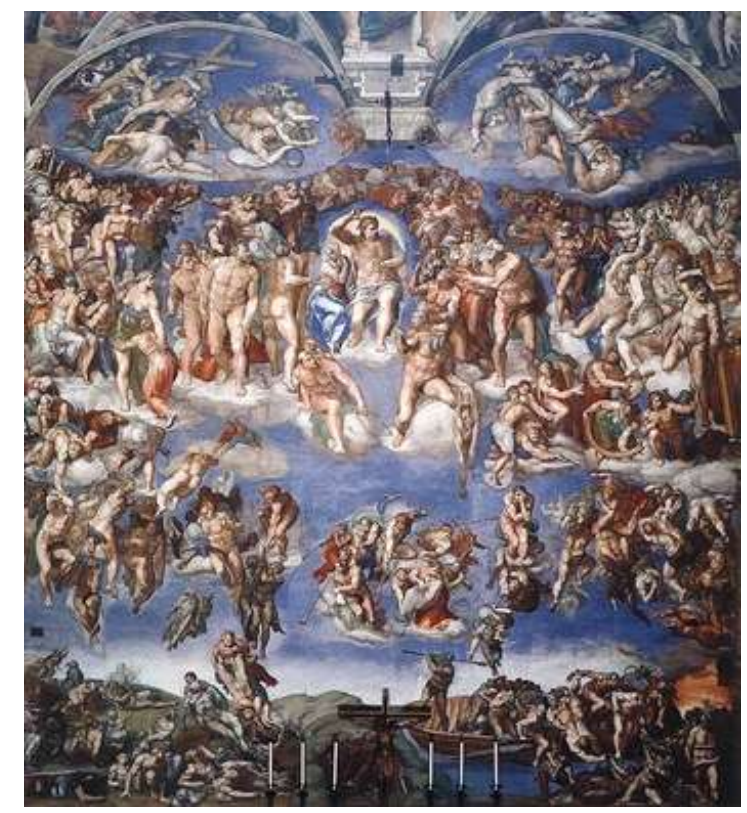

The unquantifiable realm of paradise is attractive as it allows our imagination to run wild, and conjure up our most desirable aspirations. Certainly Michelangelo accepted this cue with relish. 


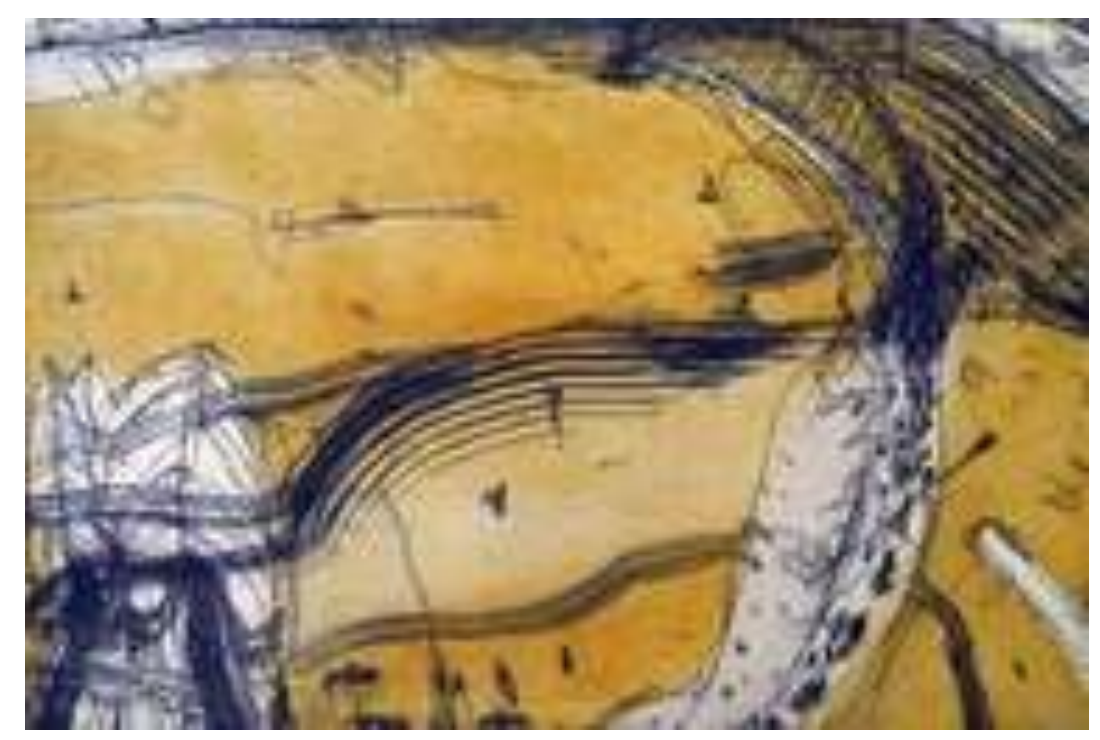

John Olsen likened North Queensland to a Mahler symphony, which is harsh, discordant and frenetic, and may suggest the gentle breezes, mosquitoes and melting heat of Cairns 


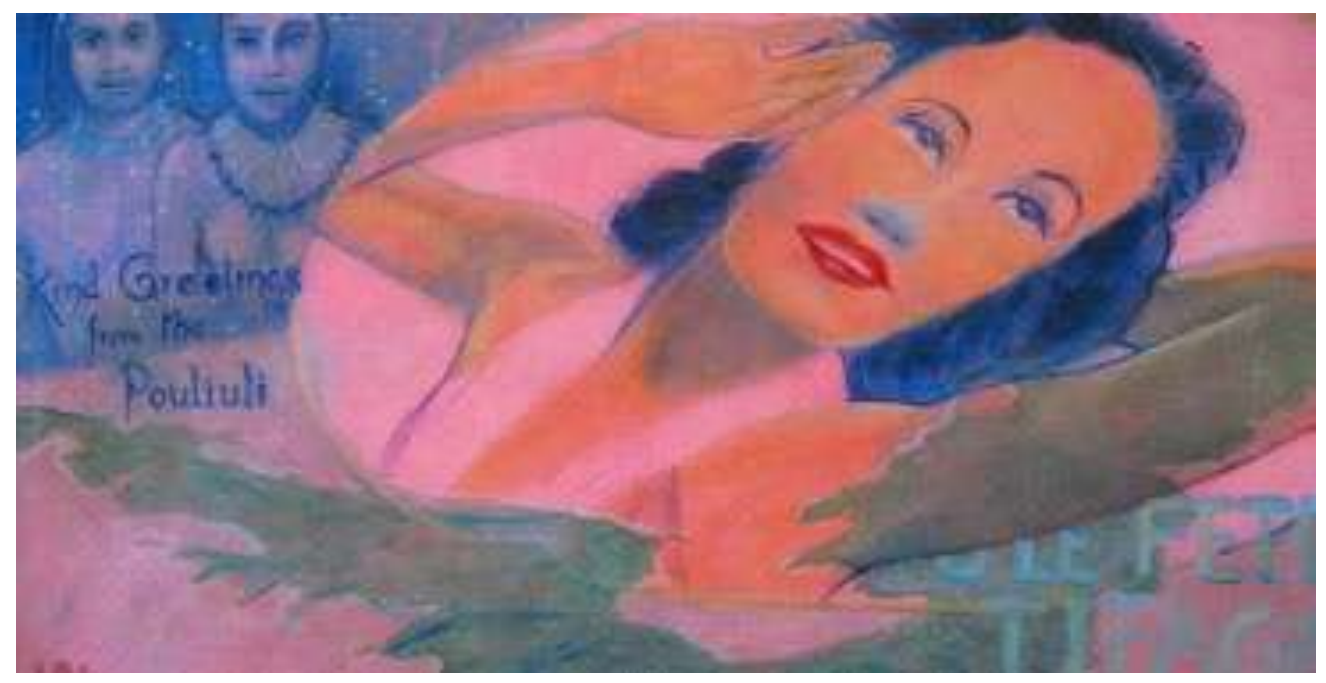

"My themes are influenced by my spiritual beliefs. Currently, I go back and forth between surrealism and realism, like a bird with two nests." 


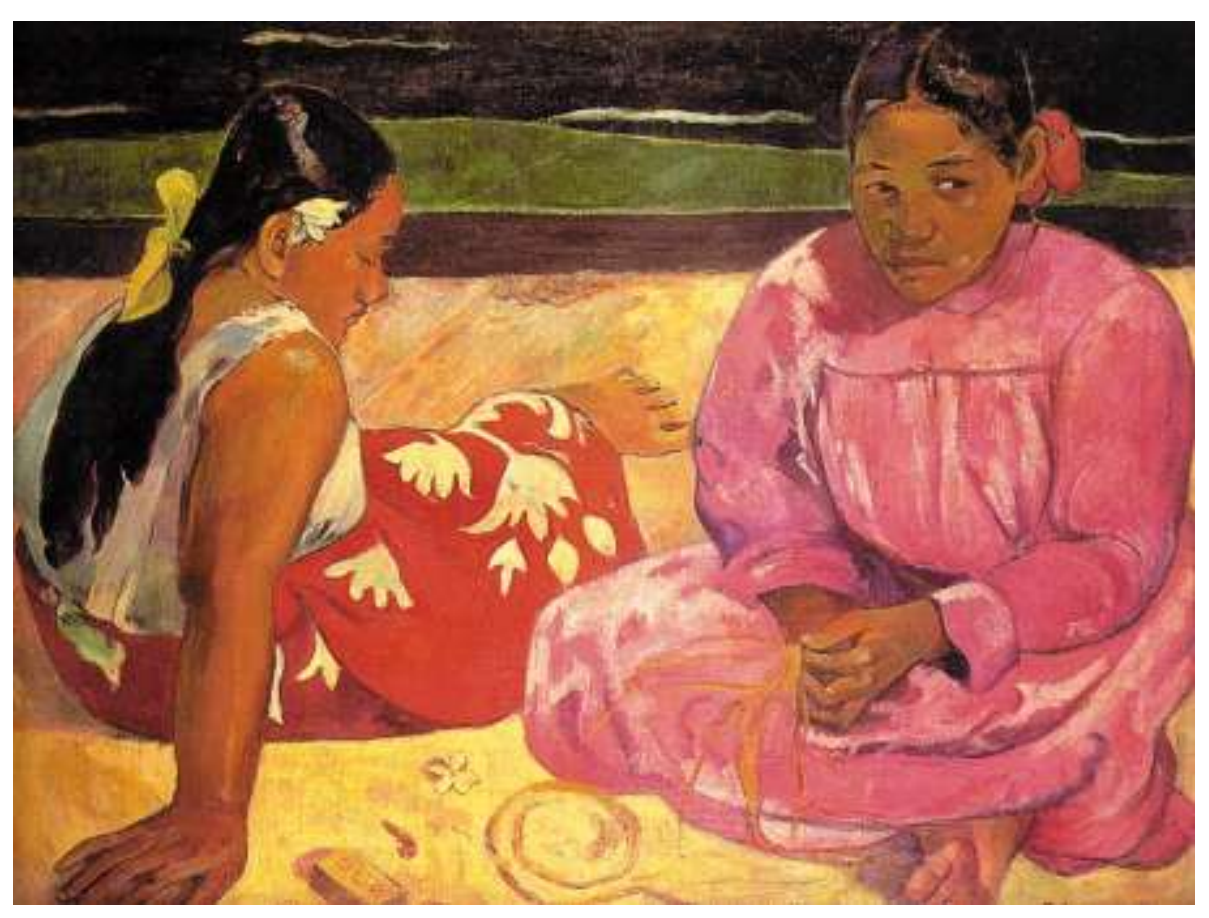

Perhaps Gauguin needed more of everything, more colour, eroticism, abandonment, freedom and moral licence to discover and devour 


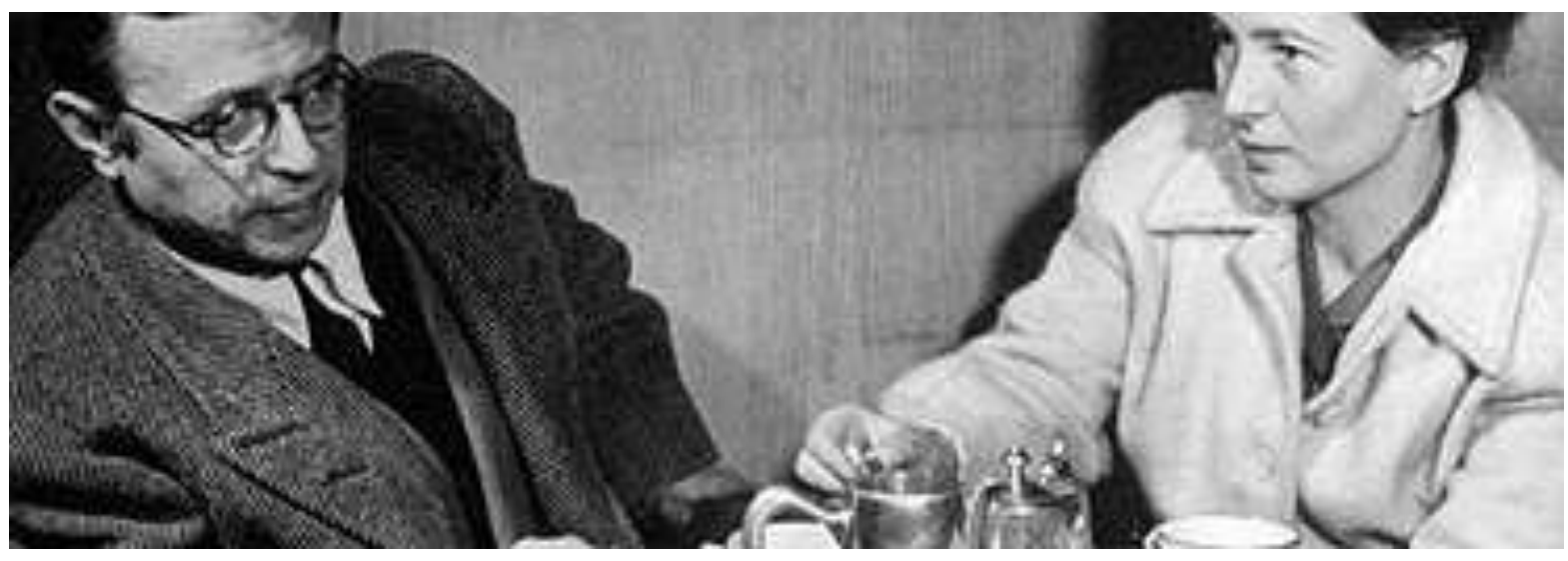

De Beauvoir took over the power of description 


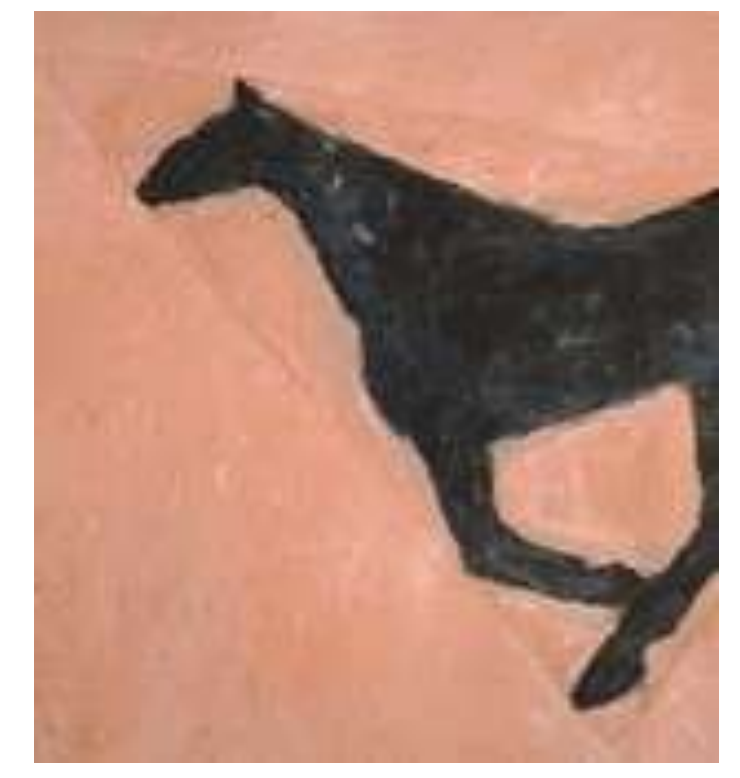

Rothenberg flies in the face of the doomed plight of women suggested by De Beauvoir. 


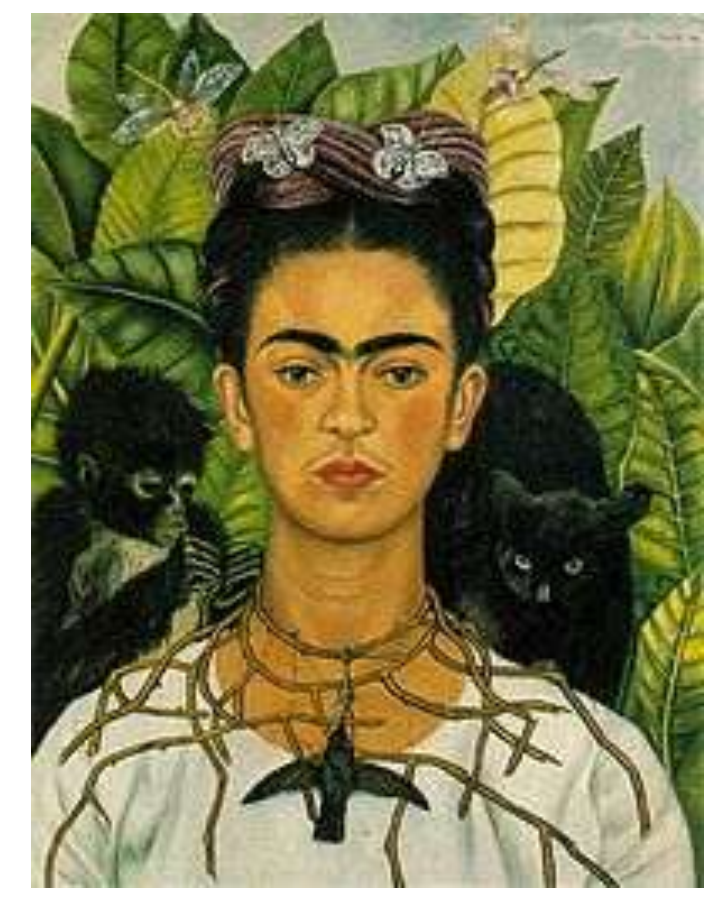

The theatre of expression taps into highly emotive realms of the feminine condition as in the case of Frida Khalo. 


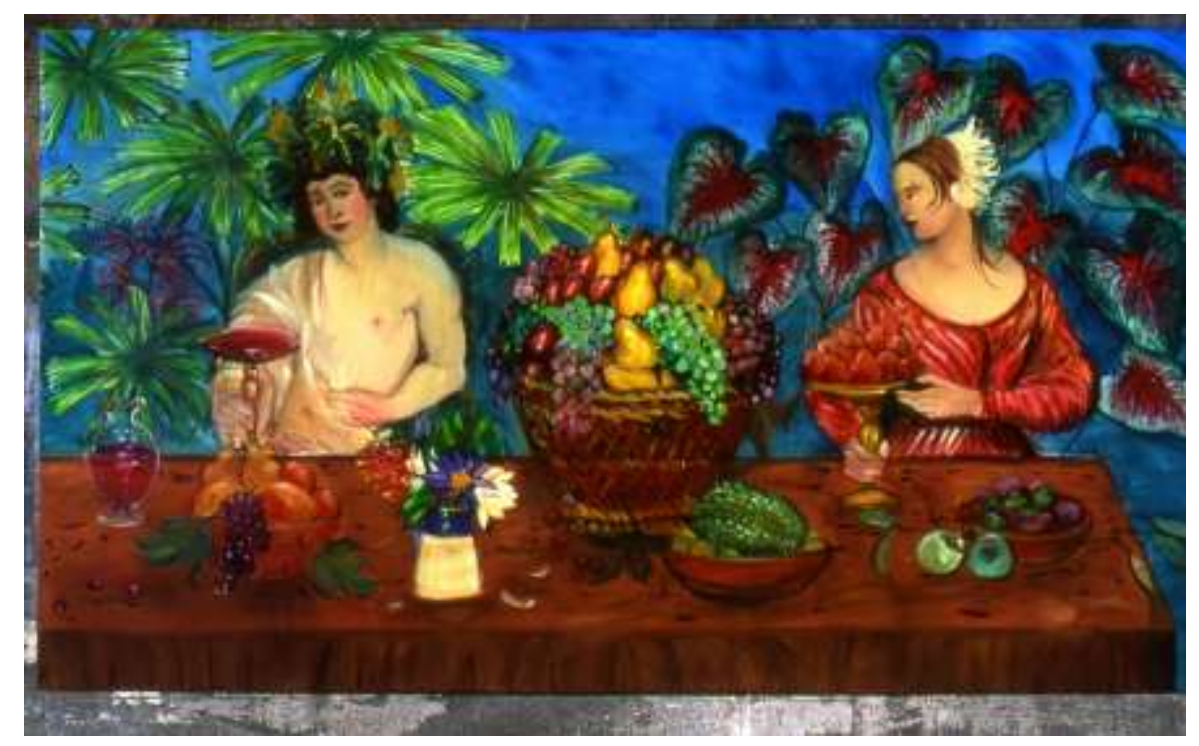

Men are from Mars and Women are from Venus comments about marriage, "Through understanding the different languages we speak it is much easier to recognize that our partners do love us and that they, in their own way, are doing their best." (Gray: 1994, p. 159) 


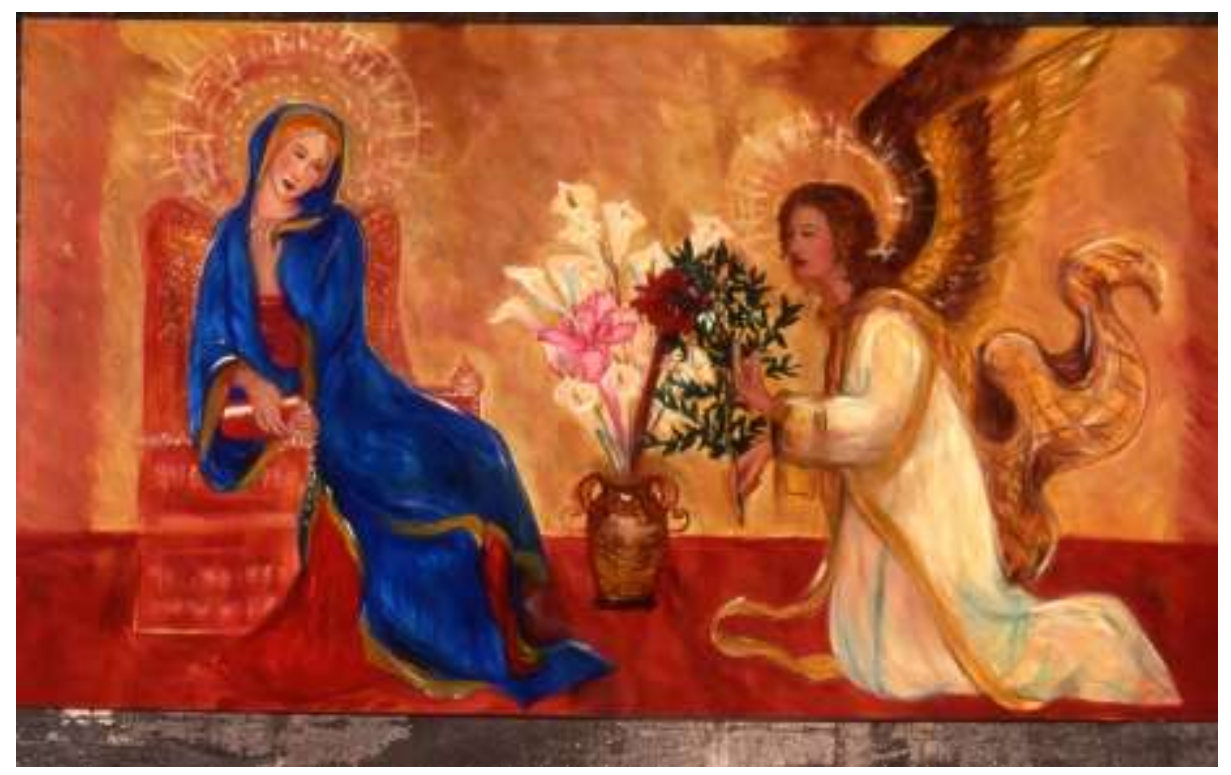

When Kant articulates his notion of the sublime and the beautiful, he is referring to truly virtuous essences of feeling, very primary reactions to things. 


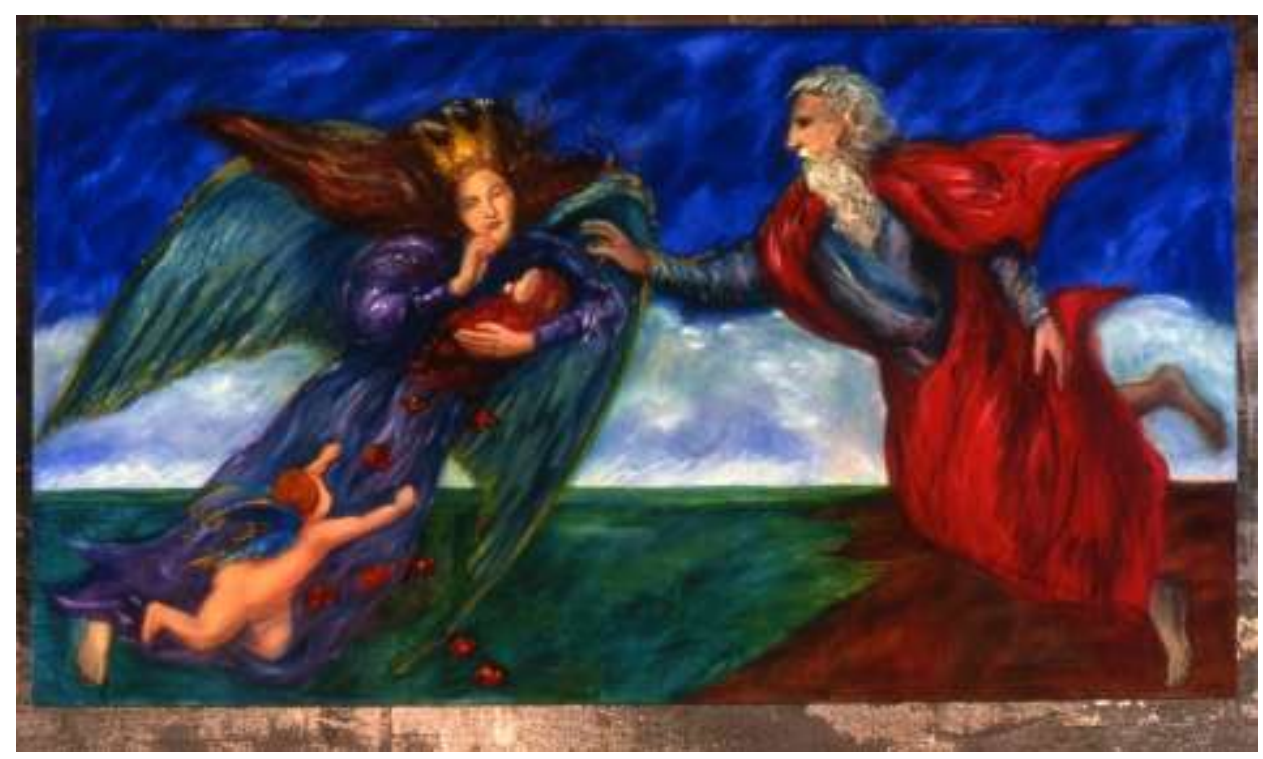

Whether the art of the Tropics will achieve Kant's proposition that true virtue can be raised by an appreciation and understanding of the beautiful and the sublime, and thus enact the principle s of humanity's beauty and dignity, is a question I am willing to ask. 


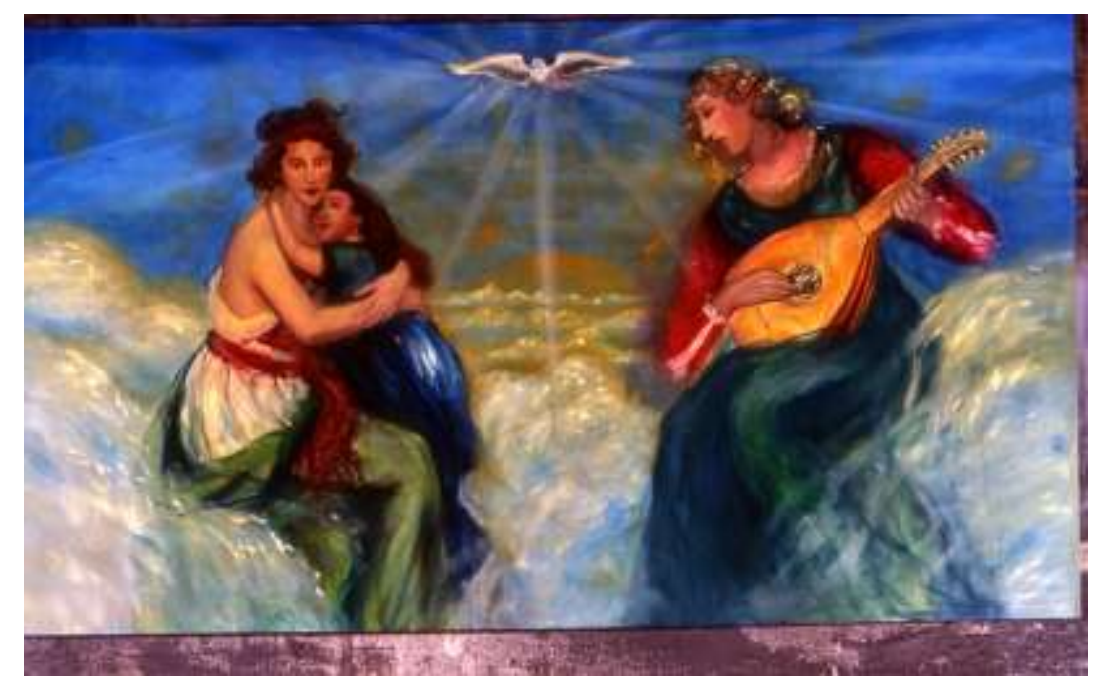

The tropics are not just an escape, or inspiration, but as necessary as the air we breathe to get some clarity and focus in our minds. 


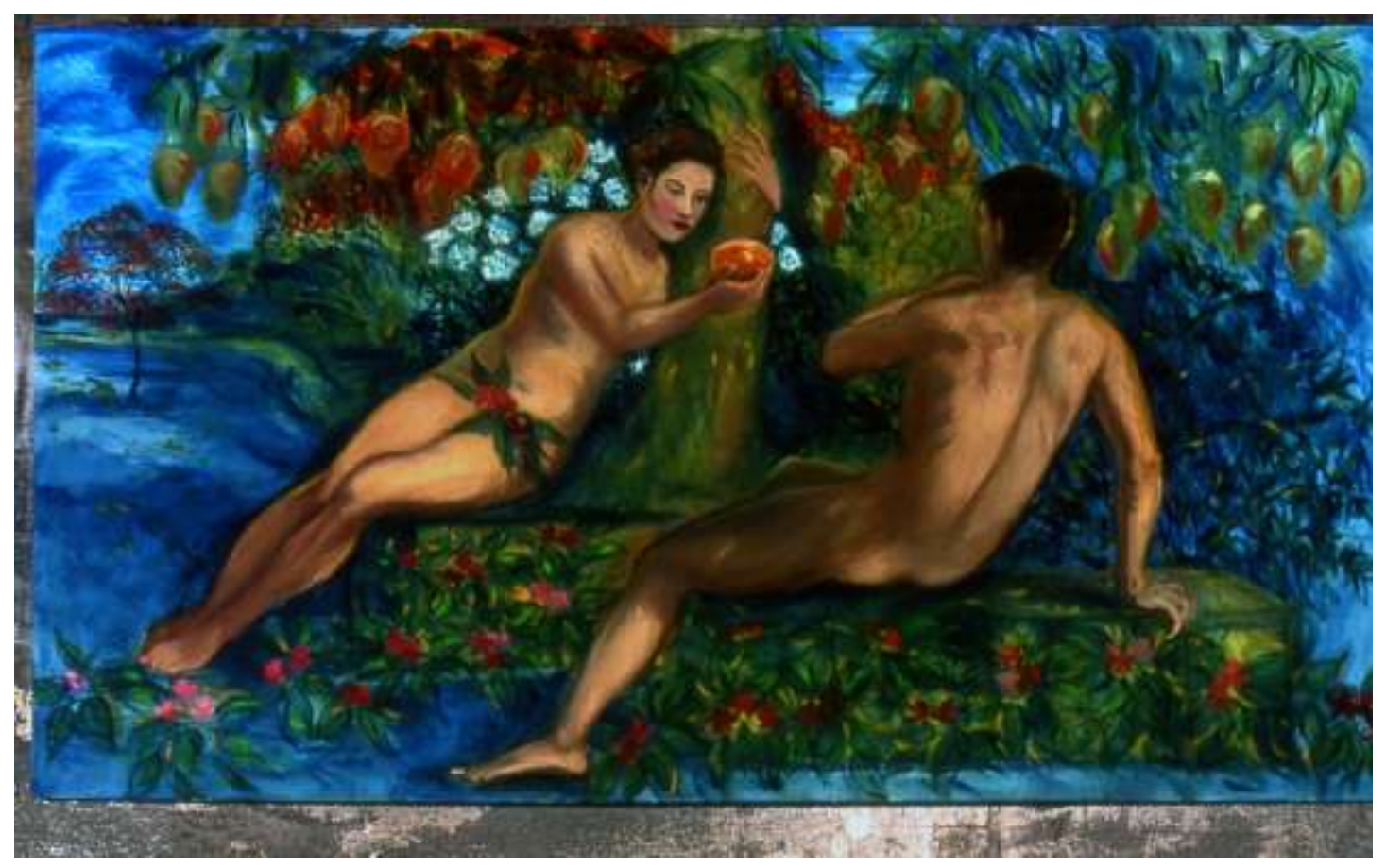

It is as though exoticism from the tropics allows a new conversation within modernism and indeed culture. 